\title{
Effect on the postprandial glycaemic level of the addition of water to a meal ingested by healthy subjects and Type 2 (non-insulin-dependent) diabetic patients
}

\author{
I. Torsdottir and H. Andersson \\ Department of Clinical Nutrition, University of Göteborg, Sahlgren's Hospital, Göteborg, Sweden
}

\begin{abstract}
Summary. The effects on postprandial glycaemic reactions of adding a glass of water to a meal were studied in 7 healthy male subjects and 20 Type 2 (non-insulin-dependent) diabetic patients for a period of up to $3 \mathrm{~h}$. The subjects were served a meal of potatoes and meat, with or without $300 \mathrm{ml}$ of water, in random order on two mornings after a 12 -h fast. The diabetic patients were considered as well-controlled or not well-controlled according to $\mathrm{HbA}_{1 \mathrm{c}}$ and blood glucose fasting values. Water addition increased the peak blood glucose $(p<0.02)$ and serum insulin $(p<0.02)$ levels in healthy subjects, and the blood glucose concentration in well-controlled diabetic patients $(p<0.02)$. The addition of water also increased the overall blood glucose response, calculated as the positive in-
\end{abstract}

cremental area, in healthy subjects by $68 \pm 25 \%(p<0.02)$ and in well-controlled diabetic patients by $40 \pm 14 \%(p<0.01)$. In poorly-controlled diabetic patients, however, the addition of water did not display significant effects, probably due to the varying fasting glycaemia in these patients. Thus, altering the physical property of a meal by dilution with water can affect the physiological responses; the results are considered to be relevant for the on-going discussion concerning the use of physiological responses to foods as a basis for diet instructions to diabetic patients.

Key words: Type 2 (non-insulin-dependent) diabetes, postprandial glycaemia, water ingestion, glycaemic index.
Physiological responses to carbohydrate foods have been suggested as a basis for instructions to diabetic patients $[1,2]$ preferable to the traditional exchange system built on quantity and molecular weight of the carbohydrate content [3]. This is a conclusion from studies which have shown varying postprandial blood glucose responses after the ingestion of comparable and isocaloric food items. The blood glucose rise following the consumption of potatoes is higher than after the consumption of most other starchy foods $[1,4,5]$. Moreover, the plasma glucose response in healthy subjects is $40-60 \%$ lower when a monosaccharide or starch is served as a solid meal, than when the same carbohydrate is given as a liquid [6]. The physical property of starchy foods has also been shown to affect blood glucose and hormonal levels following meals [7, 8].

The identification of meal characteristics that attenuate the glycaemic response is far from complete. In many countries, it is common to drink during a meal, but knowledge of the effects of adding liquids to meals on the postprandial response is limited. It has been re- ported in abstracts that adding water to meals can increase the glycaemic response in healthy subjects [9, 10]. The effect of drinking during meals on the glycaemic response in diabetic patients is, however, virtually unknown. The rate of gastric emptying affects the absorption rate of meal components and is related to the postprandial blood glucose level after meals [5, $11,12]$. Solid foods of meat, labelled by radioactive isotopes to measure gastric emptying, have been shown to empty separately from, and more slowly than labelled liquids [13, 14]. The initial gastric emptying of another protein-rich solid food (labelled egg), however, is accelerated by the addition of a liquid [5]. A liquid phase which alters the gastric emptying rate of a carbohydrate-rich meal may affect the postprandial glycaemic response.

The following study was performed to measure the glycaemic effect of changing the physical property of an ordinary lunch or dinner, including meat and potatoes, by the addition of a glass of water to be ingested with the meal. Test meals were given to one group of non- 

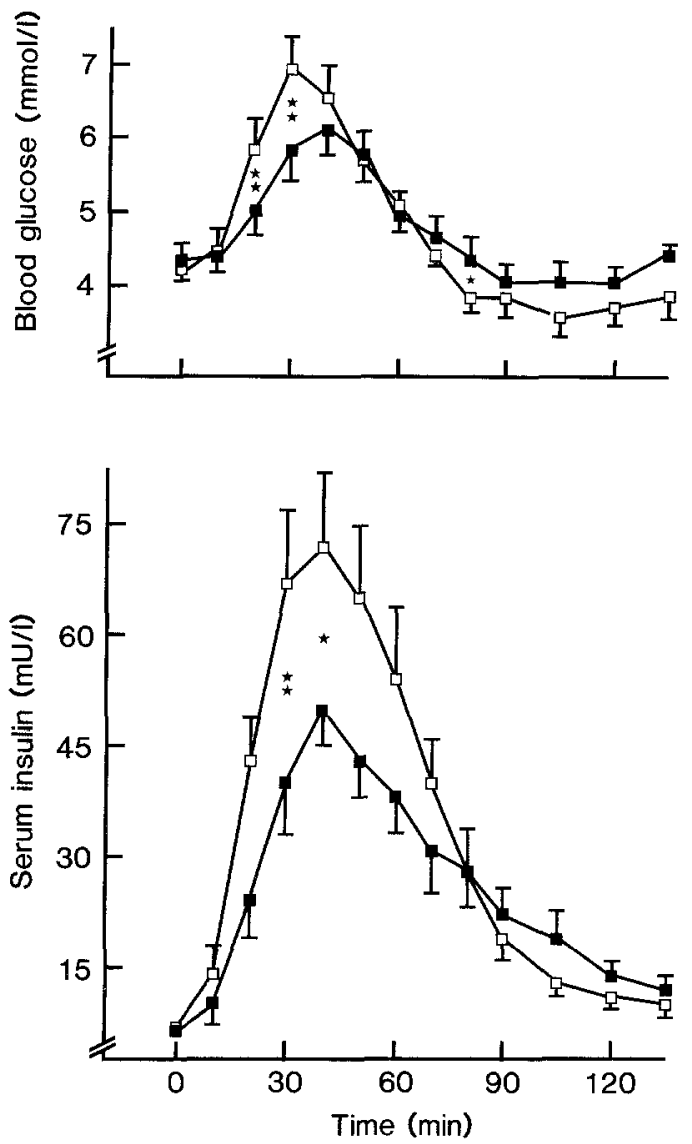

Fig. 1. Mean blood glucose and serum insulin levels before and following ingestion of meals with potatoes and meat, without $(\mathbf{0})$ or with $300 \mathrm{ml}$ of tap water ( $\square$ ), in seven healthy subjects. $I=S E M$. $*=p<0.05 ; *=p<0.02$

diabetic male subjects and to Type 2 (non-insulin-dependent) diabetic patients divided into two groups according to their $\mathrm{HbA}_{1 \mathrm{c}}$ and blood glucose fasting values.

\section{Subjects and methods}

\section{Subjects}

Seven non-diabetic male subjects (mean age 26 years, range $23-31$, mean body mass index (BMI) $23.6 \mathrm{~kg} / \mathrm{m}^{2}$, range $\left.21.0-29.4\right)$ participated in the study on two separate mornings by ingesting a meal (once with $300 \mathrm{ml}$ of water and once without) after a 12-h fast. Similarly, 20 diabetic patients were also studied, divided into two groups according to glycaemic control. One group was defined as well-controlled: twelve patients ( 10 males and 2 postmenopausal women, mean age 57 years, range $46-67$, mean BMI $25.8 \mathrm{~kg} / \mathrm{m}^{2}$, range $21.5-31.8$ ) with $\mathrm{HbA}_{1 \mathrm{c}}$ lower than $8.0 \%$ (mean $6.4 \%$, range $5.1-7.7$ ); their average blood glucose fasting value was $7.3 \mathrm{mmol} / 1$ (range $5.6-10.5$ ), and the disease had been diagnosed on an average of four years (range 2-7) before the study. Seven patients were treated with diet alone, four were under treatment with oral sulfonylurea preparations and one with a biguanide derivative. The second group was defined as poorlycontrolled: eight patients (all males, mean age 57 years, range 44-71, mean BMI $23.8 \mathrm{~kg} / \mathrm{m}^{2}$, range $19.2-27.6$ ) with $\mathrm{HbA}_{1 \mathrm{c}}$ values higher than $8.0 \%$ (mean $9.8 \%$, range $8.7-11.1$ ); their average blood glucose fasting value was $13.4 \mathrm{mmol} / \mathrm{l}$ (range $10.8-16.4$ ) and the mean disease duration was 11 years (range 4-21). One of these patients had been treated with diet only before and during the study; five were treated with sulfonylurea and biguanide, and two with either biguanide or sulfonylurea. The patients had their usual morning tablets before each test.

All the subjects were asked to keep their usual habits in diet and physical activity the days before and during the tests.

The subjects received written information about the study and gave their consent. The study was approved by the Local Ethical Committee at Sahlgren's Hospital.

\section{Test meals}

The test meal eaten by 7 healthy subjects and 20 diabetic patients was composed as a lunch or dinner with fresh potatoes boiled in water for $25 \mathrm{~min}$ and then peeled and weighed to the used amount $(280 \mathrm{~g})$. The potatoes were served with beef $(80 \mathrm{~g}$, inside round) fried in margarine $(5 \mathrm{~g})$. The nutritional content of the meal was calculated from food composition tables [16]. Each meal consisted of $415 \mathrm{kcal}$, with $55 \%$ of the energy as carbohydrate. The calculated amount of dietary fibre was $2.8 \mathrm{~g}$. The meal was ingested on 2 separate occasions by each subject, once with a glass of tap water $(300 \mathrm{ml})$ and once without. Supplementation of the meal with a glass of tap water was randomly determined. The subjects were asked to drink the water during the meal and maintain a similar time schedule for both test meals. No other food or drink ingestion, and no smoking was permitted on the test mornings.

\section{Analytical methods}

Blood samples were drawn through an indwelling intravenous catheter before the intake of the test meal and at regular intervals up to $180 \mathrm{~min}$ after the meal. Blood glucose was analysed by the glucose oxidase method (Merck, Darmstadt, FRG) and serum insulin by a radioimmunoassay technique (Diagnostic products corporation, Los Angeles, Calif., USA). The effect of the water addition on the overall glycaemic response was calculated as the change (per cent) in the positive incremental area under the blood glucose curve. The time at which the maximal blood glucose value was reached was also noted. $\mathrm{HbA}_{1 \mathrm{c}}$ was analysed by an ion-exchange HPLC-technique (normal range $3.4-5.4 \%$ ).

\section{Statistical analysis}

The two-tailed Wilcoxon signed ranks test, paired observations, was used for calculation of differences and a $p$ value $<0.05$ was considered statistically significant [17]. The data are given as mean \pm SEM. The Systat program (Systat 4.0, statistics \& graphics) was used for all the calculations (Systat, Evanston, Ill., USA).

\section{Results}

\section{Healthy subjects}

Figure 1 shows the average blood glucose and serum insulin curves following the test meals. Both curves were higher after the meal with water compared to that without added water. The overall glucose response to the meal taken with a glass of water was $68 \pm 25 \%$, higher than that after the reference meal $(p<0.02)$. The time taken to reach the maximal blood glucose or serum in- 


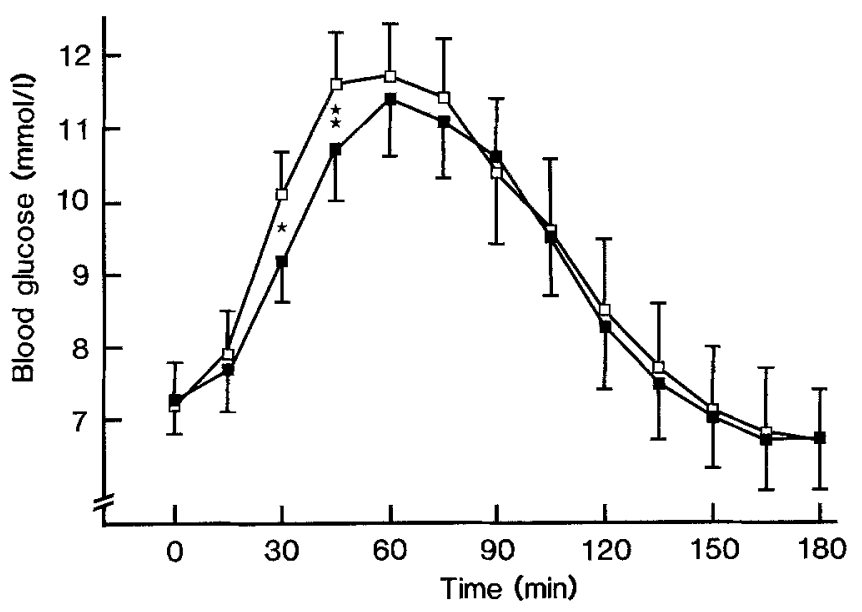

Fig. 2. Mean blood glucose levels before and following ingestion of meals with potatoes and meat, without (ם) or with $300 \mathrm{ml}$ of tap water (ㅁ), in twelve well-controlled Type 2 (non-insulin-dependent) diabetic subjects. $\mathrm{I}=\mathrm{SEM} . *=p<0.05 ; *=p<0.02$

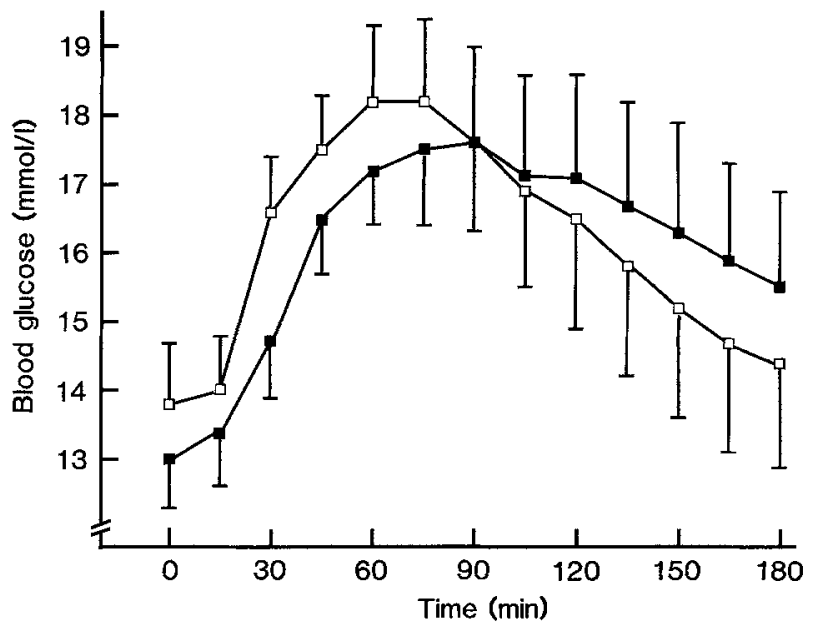

Fig. 3. Mean blood glucose levels before and following ingestion of meals with potatoes and meat, without $(\square)$ or with $300 \mathrm{ml}$ of tap water $(\square)$, in eight Type 2 diabetic patients $\left(\mathrm{HbA}_{1 \mathrm{c}}>8.0 \%\right.$, blood glucose fasting value $>10.5 \mathrm{mmol} / 1) . \mathrm{I}=\mathrm{SEM}$

sulin value did not differ significantly following the 2 meals, $36 \pm 3 \mathrm{~min}$ and $37 \pm 4 \mathrm{~min}$, respectively, after the meal with a glass of water, as compared to $41 \pm 3 \mathrm{~min}$ and $43 \pm 4 \mathrm{~min}$ following that without $(p>0.05)$.

\section{Diabetic patients}

The 12 well-controlled patients showed a higher increase in blood glucose after the meal with a glass of water than after the meal without added water, see Figure 2. The glucose response to the meal with the glass of water was $40 \pm 14 \%$ higher than the response to the other meal $(p<0.01)$. The maximal value in blood glucose concentration after the meal with water was reached earlier, at $58 \pm 5 \mathrm{~min}$, than after the meal with no drink, $69 \pm 6 \mathrm{~min}(p<0.05)$.
Ingestion of the test meals by 8 patients with fasting blood glucose values above $10.5 \mathrm{mmol} / \mathrm{l}$ and $\mathrm{HbA}_{1 \mathrm{c}}$ above $8.0 \%$ resulted in the blood glucose responses shown in Figure 3. The overall glucose response was $12 \pm 14 \%$ lower following the meal with a glass of water than following the response to the reference meal (NS, $p>0.05$ ). The times at which maximal blood glucose levels were reached did not differ significantly, but were $69 \pm 10 \mathrm{~min}$ after the meal with a glass of water and $88 \pm 13$ min after that without $(p>0.05)$.

\section{Discussion}

The present study shows lower glycaemic response in healthy subjects and in well-controlled diabetic patients after a meal without a glass of water, compared to the response after an identical meal ingested with $300 \mathrm{ml}$ of tap water. These differences in the glycaemic responses seem to be comparable to the different glycaemic responses of fibre-depleted and fibre-containing meals $[11,18,19]$.

To explain the effect of the addition of water to a meal, gastric emptying must be taken into consideration. A more rapid gastric emptying of a meal's carbohydrate-rich solid food, induced by a glass of water, was followed by a higher blood glucose level (unpublished observations). The effect of water addition in the present study on the glycaemic response might, therefore, be explained by an acceleration of the gastric emptying rate of carbohydrates.

A disturbed control of gastric emptying has been described as a rare late complication to diabetes [20, 21]. An impaired gastric emptying pattern of solids and a disturbed ability of the stomach to distinguish solids from liquids have been observed in diabetic patients as compared to healthy controls $[22,23]$, while other investigations report no such findings in diabetic patients [24]. A different mechanism of action in the digestion process and an altered control of the gastric emptying may explain the proportionally lower difference between the glycaemic responses in well-controlled diabetic patients following ingestion of test meals with varying water contents, as compared to younger, healthy subjects. Disturbed digestion might also explain why no effect of water on the glycaemic response was found in the group of poorly-controlled diabetic patients. A more convincing reason, however, seems to be the difficulties in studies of patients with high blood glucose fasting values. High and varying blood glucose fasting values have been shown to be disturbing factors in the evaluation of effects from different meals [25]. This is supported by a negative correlation between the preprandial blood glucose level and the glycaemic response [26]. Reduced renal excretion of excess glucose due to a lack of water may partially explain the late postprandial hyperglycaemia following the test meal without added water in the group of poorly-controlled 
diabetic patients. The findings in this group should be viewed with caution, as they may be a result of poorlycontrolled diabetes.

Blood glucose responses to various foods can be reported in absolute values, as in the present study, or as a change from the fasting value $[5,8]$. The latter method gives a decreased variation in the blood glucose response, as can be seen in our group of well-controlled diabetic patients. The average SEM for the postprandial values was $0.5 \mathrm{mmol} / 1$ (range, $0.1-0.8 \mathrm{mmol} / 1$ ), as compared to $0.8 \mathrm{mmol} / 1$ (range, $0.5-1.0 \mathrm{mmol} / 1$ ) when absolute values were used. The method also affected the statistical evaluation, as the difference between the postprandial responses following the two meals was clearer when the change from the fasting values was used (significant at $15(p<0.05), 30(p<0.02)$ and $45 \mathrm{~min}(p<0.01)$ ). Furthermore, use of the glycaemic index, which accounts for the positive incremental area [1], yields a lower inter-subject variation [26]. The importance of the method of calculation for the interpretation of postprandial glucose levels has been pointed out earlier by Gannon and Nuttall [27]. In the present study, however, these methods of calculation have not altered the primary results.

The glycaemic index was developed in order to be used as a method for classifying carbohydrate foods according to their effect on the postprandial blood glucose $[1,26]$. The concept is based on a standard calculation method, but it has been pointed out that the composition of the meal and the way in which the food is prepared may alter the predicted glucose concentrations [27-29]. This study has added water to the long list of factors capable of affecting the glycaemic responses to foods. The clinical relevance of the glycaemic index system [1] has been questioned because of the many different factors which may influence the postprandial blood glucose and which have not been sufficiently studied [25, 27-29].

Drinking during meals might have an impact on the control of energy intake. A positive correlation has been observed between gastric transit time and satiety [30] and the texture of food has been shown to affect satiety after meals [31, 32]. Furthermore, the ingestion of a carbohydrate food which gives a low postprandial glycaemic level also delays the return of hunger after the meal in comparison to a high-response food [33]. A drink with a meal, resulting in a more rapid gastric emptying of the meal as well as a higher postprandial glycaemic level (as shown in our study), may therefore affect the short-term feeling of satiety and stimulate energy intake.

In conclusion, our results show that altering the physical property of a meal by the intake of a liquid, demonstrated in this experiment by a glass of water, increases the glucose response in healthy young subjects, as well as in well-controlled Type 2 diabetic patients. No significant effect was seen in poorly-controlled Type 2 diabetic patients. The results are considered to be of importance in the attempts to gain further knowledge of factors affecting physiological responses to meals.

Acknowledgements. The financial support of the Swedish Council for Forestry and Agricultural Research (L 24) and of the Swedish Nutrition Foundation is gratefully acknowledged. The authors thank S.Lindstrand for skillful technical assistance, and G. Attman and the physicians at the Health Centre in Mölndal for kindly informing their patients about our study.

\section{References}

1. Jenkins DJA, Jenkins LA, Wolever TMS, Josse RG, Wong GS (1984) The glycaemic response to carbohydrate foods. Lancet II: 388-391

2. Riccardi A, Rivellese AA (1987) New indices for selection of carbohydrate foods in the diabetic diet: hopes and limitations. Diabetic Med 4: 140-143

3. American Diabetes Association (1977) A guide for professionals: the effective application of exchange lists for meal planning. American Diabetes Association and American Dietetic Association, New York

4. Crapo PA, Reaven G, Olefsky J (1977) Postprandial plasma-glucose and -insulin responses to different complex carbohydrates. Diabetes 26: 1178-1183

5. Torsdottir I, Alpsten M, Andersson D, Brummer RJM, Andersson $H$ (1984) Effect of different starchy foods in composite meals on gastric emptying rate and glucose metabolism I Comparisons between potatoes, rice and white beans. Hum Nutr Clin Nutr 38C: 329-338

6. Crapo PA, Reaven G, Olefsky J (1976) Plasma glucose and insulin responses to orally administered simple and complex carbohydrates. Diabetes 25: 741-747

7. O'Dea K, Nestel PJ, Antonoff L (1980) Physical factors influencing postprandial glucose and insulin responses to starch. Am J Clin Nutr 33: 760-765

8. Simpson RW, McDonald J, Wahlqvist ML, Atley L, Outch K (1985) Food physical factors have different metabolic effects in nondiabetics and diabetics. Am J Clin Nutr 42: 462-469

9. Torsdottir I, Halferkamps ICH, Andersson H (1985) Effects of water and particle size in composite meals on blood glucose and serum insulin responses in non-diabetic subjects. Third International Symposium Diabetes and Nutrition Study Group of the EASD. (Booklet of abstracts)

10. Kronsbein P, Chantelau E, Berger M (1985) Alteration of the glycaemic index of crisp-bread by simultaneous intake of tap water or butter. XII Congress of the IDF. (Abstract) Diabete Res Clin Pract [Suppl 1]: S 320

11. Holt S, Heading RC, Carter DC, Prescott LF, Tothill P (1979) Effect of gel fibre on gastric emptying and absorption of glucose and paracetamol. Lancet I: 636-639

12. Mourot J, Thouvenot P, Couet C, Antoine JM, Krobicka A, Debry $G$ (1988) Relationship between the rate of gastric emptying and glucose and insulin responses to starchy foods in young healthy adults. Am J Clin Nutr 48: 1035-1040

13. Moore JG, Christian PE, Coleman RE (1981) Gastric emptying of varying meal weight and composition in man. Evaluation by dual liquid- and solid-phase isotopic method. Dig Dis Sci 26: 16-22

14. Collins PJ, Horowitz M, Cook DJ, Harding PE, Shearman DJC (1983) Gastric emptying in normal subjects - a reproducible technique using a scintillation camera and computer system. Gut 24: $1117-1125$

15. Kroop HS, Long WB, Alavi A, Hansell JR (1979) Effect of water and fat on gastric emptying of solid meals. Gastroenterol 77: $997-1000$ 
16. The Swedish National Food Administration (1986) Food composition tables. Liber tryck AB, Stockholm

17. Conover WJ (1980) Practical nonparametric statistics. Wiley, New York

18. Jenkins DJA, Taylor RH, Wolever TMS (1982) The diabetic diet, dietary carbohydrate and differences in digestibility. Diabetologia 23: 477-484

19. Hagander B, Schersten B, Asp N-G, Sartor G, Agardh C-D, Schrezenmeir J, Kasper H, Ahren B, Lundquist I (1984) Effect of dietary fibre on blood glucose, plasma immunoreactive insulin, $\mathrm{C}$ peptide and GIP responses in non insulin dependent (Type 2) diabetics and controls. Acta Med Scand 215: 205-213

20. Kassander P (1958) Asymptomatic gastric retention in diabetes: gastro-paresis diabeticorum. Ann Intern Med 48: 797-812

21. Zitomer BR, Gram HF, Kozak GP (1968) Gastric neuropathy in diabetes mellitus: clinical and radiological observations. Metabolism 17: 199-211

22. Bertrand J, Danquechin Dorval E, Platel A (1982) Gastric emptying time as measured by radiopaque markers in control and diabetic patients. In: Wienbeck M (ed) Motility of the digestive tract. Raven, New York, pp 363-367

23. Campbell JW, Heading RC, Tothill P, Buist TAS, Ewing DJ, Clarke BF (1977) Gastric emptying in diabetic autonomic neuropathy. Gut 18: 462-467

24. Scarpello JHB, Barber DC, Hague RV, Cullen DR, Sladen GE (1976) Gatric emptying of solid meals in diabetics. Br Med J 2: 671-673

25. Nielsen PH, Nielsen GL (1989) Preprandial blood glucose values: influence on glycemic response studies. Am J Clin Nutr 49: $1243-1246$

26. Wolever TMS, Nuttall FQ, Lee R, Wong GS, Josse RG, Csima A, Jenkins DJA (1985) Prediction of the relative blood glucose response of mixed meals using the white bread glycemic index. Diabetes Care 8: $418-428$
27. Gannon MC, Nuttall FQ (1987) Factors affecting interpretation of postprandial glucose and insulin areas. Diabetes Care 10:759-763

28. Nathan DM (1987) The glycemic index: Meat and potatoes or just gravy. Diabetes Care 10: 524-525

29. Hollenbeck CB, Coulston AM, Reaven GM (1986) Glycemic effects of carbohydrates: A different perspective. Diabetes Care 9: 641-647

30. Wilmhurst P, Crawley JCW (1980) The measurement of gastric transit time in obese subjects using ${ }^{24} \mathrm{Na}$ and the effects of energy content and guar gum on gastric emptying and satiety. Br J Nutr 44: $1-6$

31. Haber GB, Heaton KW, Murphy D, Burroughs LF (1977) Depletion and disruption of dietary fibre. Effects on satiety, plasma-glucose, and serum-insulin. Lancet 2: 679-682

32. Bolton RP, Heaton KW, Burroughs LF (1981) The role of dietary fiber in satiety, glucose, and insulin: studies with fruit and fruit juice. Am J Clin Nutr 34: 211-217

33. Leathwood P, Pollet P (1988) Effects of slow release carbohydrates in the form of bean flakes on the evolution of hunger and satiety in man. Appetite 10:1-11

Received: 5 October 1988

and in revised form: 5 February 1989

Dr. I. Torsdottir

Department of Clinical Nutrition

University of Göteborg

Sahlgren's Hospital

S-413 45 Göteborg

Sweden 